\title{
Delineating the fluvial channel system in the Upper Triassic formation of the Elward area in the Syrian Euphrates Graben using 3-D seismic attributes
}

\author{
Mohammad Alsouki • Riad Taifour • \\ Omar Al Hamad
}

Received: 4 August 2013/ Accepted: 20 February 2014/Published online: 15 March 2014

(C) The Author(s) 2014. This article is published with open access at Springerlink.com

\begin{abstract}
D seismic data were used to evaluate the reservoir in the Mulussa $\mathrm{F}$ formation in the Elward area and to discover new drillable locations by delineating the fluvial channel system and the features of its facies. Seismic attributes such as relative acoustic impedance, coherency volume and reflection strength were considered. The attribute maps revealed different types of channels such as braided, meandering and anastomosing channels. They also revealed fluvial features such as point bars, Ox-Bows and crevasse splays, which are considered potential points of hydrocarbon accumulation due to the abundance of sandy bodies. The map of relative acoustic impedance demonstrated that the sandstone beds have high impedance, whereas the shale beds have low impedance. In fact, well data indicated that the shaly beds were surrounded by sandy beds, and their thickness was in the range of 20-25 m within the Mulussa F formation. The coherency attribute showed some of the meandering tributary channels that were not seen on the relative acoustic impedance map. The abundance of fluvial channels in the Euphrates region indicates a large water discharge during the deposition of the Mulussa F formation because of the wet climate prevailing during the Upper Triassic.
\end{abstract}

\footnotetext{
M. Alsouki ( $₫) \cdot$ O. Al Hamad

Syrian Petroleum Company, Damascus, Syria

e-mail: mfs_dam7@yahoo.com

O. Al Hamad

e-mail: spcgenman@spc-sy.com

R. Taifour

Geology Department, Sciences Faculty, University of Damascus, Damascus, Syria

e-mail: rtaifour@ureach.com
}

Keywords Fluvial - Channel - Seismic - Attributes · Euphrates

\section{Introduction}

The area of study is located in the middle part of the Euphrates Graben area, between the Elward and the Jido Grabens and within the Euphrates Graben, situated to the east of Syria (Fig. 1a). This Graben is located in the northern part of the Arabian Plate, and it contains significant petroleum reserves. Elward Field is considered one of the most important structural traps that produces oil from the Mulussa F formation, which dates from the Upper Triassic.

The area has accumulated a large amount of sediment from the Palaeozoic to the present. The Mulussa F formation consists of clastic sediments with a narrow thickness range of 280-320 m (Fig. 2), as indicated by the well data from the study area. It is considered the most important reservoir sequence along with the Lower Cretaceous sandy Rutba formation. The Mulussa F and Rutba reservoirs retain $80-90 \%$ of the hydrocarbon volume within the Graben area, as indicated in regional studies. The reservoir characteristics of Mulussa $\mathrm{F}$ in Elward Field are fairly good. The net/gross ratios are usually approximately $35 \%$, and the average porosities are in the range of 20-30\%.

The high-quality 3-D seismic used in this study was a powerful tool that made it possible to interpret the sedimentary features and obtain a better understanding of the depositional environment. Different interpretation techniques, such as conventional seismic interpretation, were used to extract various types of attributes, such as the relative acoustic impedance and coherency attributes that were required for detection of the subtle channel features that constitute the main goal of our study. Thus, the aim of

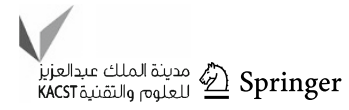




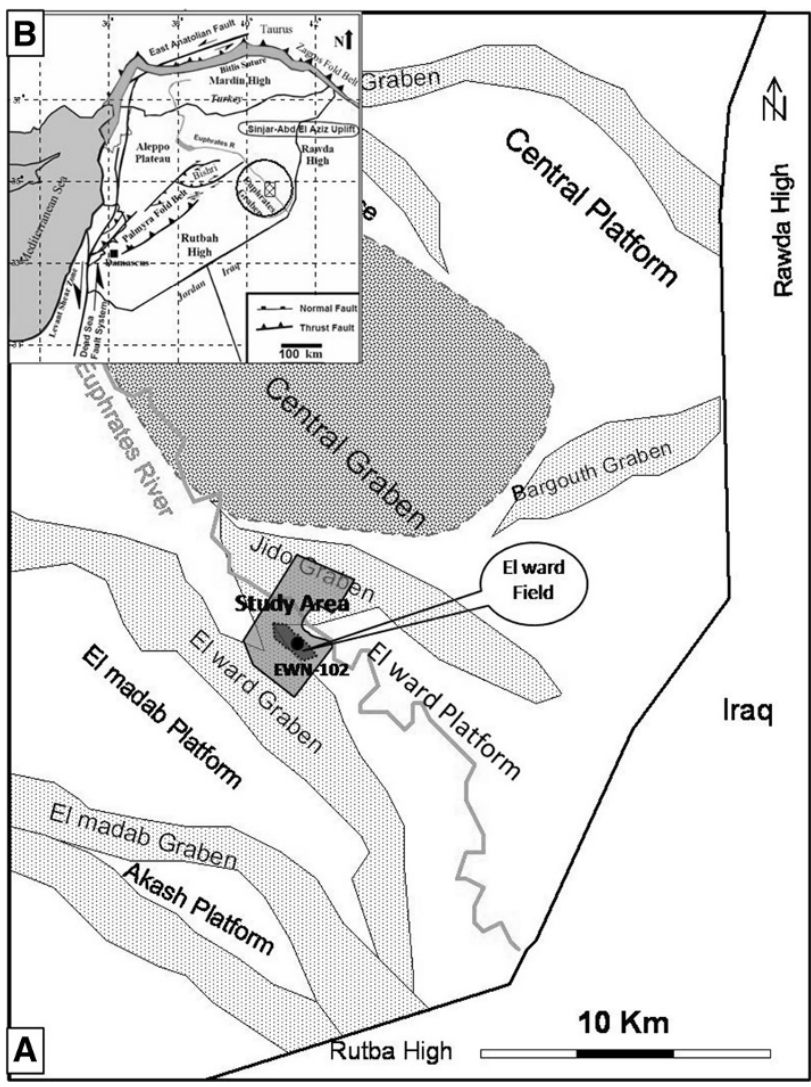

Fig. 1 a Location of study area on a tectonic map of the Euphrates Graben. b Syrian tectonic map showing the Arabia-Eurasia collision line

this paper is to delineate the fluvial channel system in the Mulussa $\mathrm{F}$ formation and to describe the features of its facies, which may form a potential stratigraphic trap.

\section{Geological and tectonic setting of the Euphrates Graben}

The Syrian Euphrates Graben is part of the Euphrates fault system, which is located in the northern part of the Arabian plate near the edge of the Eurasia/Arabian plate collision (Brew et al. 2001b). It is characterised by sets of extensional faults that give rise to a series of horst and graben features. The Arabian Plate contacts the Eurasia plate on a roughly north-north westerly direction (McClusky et al. 2000). This collision is obvious because of the active transformation and convergent plate boundaries that are currently proximal to Syria (Fig. 1b). The events that occurred at these boundaries have largely dominated the Paleozoic tectonics of Syria, particularly the Mesozoic-Cenozoic tectonics.

The Euphrates Graben is a fault-bounded failed rift that has been studied extensively by Litak et al. 1997 showed that the Euphrates Fault System is a related, but lessdeformed zone of an extension that extends from the Iraqi border in the southeast to the Turkish border in the northwest and includes the Euphrates Graben.

A Turonian-Coniacian age unconformity most likely marked by a pre-rift uplift was extensively developed in the Euphrates Graben, and the underlying limestone was eroded and dolomitised. Coniacian rifting that resulted in approximately $6 \mathrm{~km}$ of extension and an indefinite amount of strikeslip movement was accommodated by a distributed system of steep normal faults (Litak et al. 1998). The syn-rift carbonate deposition culminated in the Campanian to early Maastrichtian with the deposition of marly limestones within the graben. Rift-related extension stopped during the Maastrichtian.

The Paleogene was marked by widespread thermal subsidence as the lithosphere re-established thermal equilibrium after rifting (Brew et al. 2001a).

The stratigraphy of the Euphrates Graben generally records a clastic-dominated Palaeozoic section underlying Triassic to Meocene carbonate rocks and evaporites interbedded with lesser amounts of sandstone and shale (Fig. 2). Early Palaeozoic subsidence led to the deposition of Cambro-Ordovician clastic sediments throughout most of the Euphrates Graben along an east-facing continental margin (Best et al. 1993).

Mulussa $\mathrm{F}$ was deposited during the tectono-depositional phase of the Palmyrides Basin adjacent to the Euphrates Graben. The tectonic extensional events that took place in the Jurassic period led to complete erosion of Jurassic formations, and partial erosion of the Mulussa $\mathrm{F}$ formation in the Euphrates Graben produced an unconformity surface over the Mulussa $\mathrm{F}$ Formation called the BKL (Base Cretaceous Lower) (Fig. 2).

Based on well data from the Euphrates Graben, Mulussa $F$ sediments represent a regressive clastic cycle during the Upper Triassic, which consists of marine dolomites and shales in the basal section, passing upward into the coastal plain and fluvial claystones and sandstones. Mulussa $\mathrm{F}$ extends laterally from the continental clastic sediment overlying the Doubayat Formations in the southern Euphrates Graben to a 300-m thick layer of regression coastal and fluvial sediments in the study area, and it gradually changes to marine carbonates and clastics in the distal areas near the Palmyride Basin in most of the western Euphrates Graben. The actual thickness of this formation is largely controlled by the rate of erosion at the BKL. This facies distribution suggests that the sediment comes from southern and south western areas in the most interior parts of the Arabian Platform (Brew et al. 2001a).

The time map of the Mulussa F formation top in the study area (Fig. 3) shows three structural units: the Elward Platform and the Jido and El Ward Grabens, which are oriented east-west to northwest-southeast and which are parallel to the central Euphrates Graben. These units form an intracratonic rift system that developed within the northern Arabic 


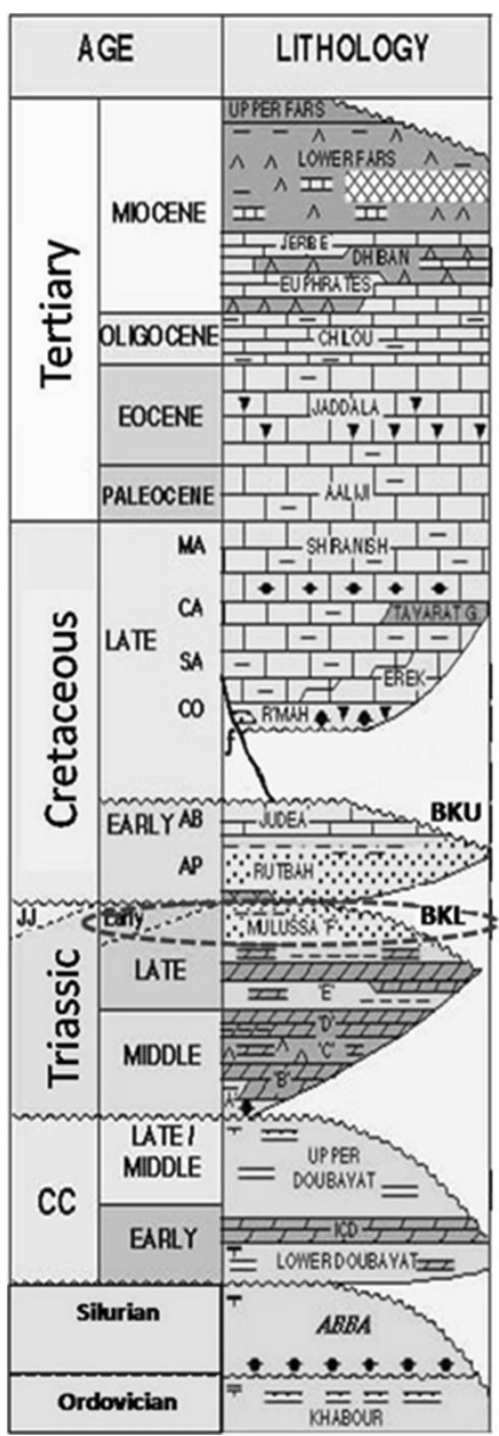

Fig. 2 Mulussa F formation and the unconformity surface (BKL) of the stratigraphic column of the study area

plate in the beginning of late Cretaceous (Coniacian), separating the Rutba High to the south from the Rawda High to the east (Figs. 1, 3). The upper cretaceous formations (Lower and Upper Shiranish) in the aforementioned Grabens are mainly dominated by carbonates with shaly beds. These grabens are considered to be a "kitchen" for the surrounding Jido and Elward Fields, and they form potential stratigraphic traps within the Mulussa $\mathrm{F}$ formation.

\section{Methodology}

Seismic data set

The seismic data were acquired using a sercel SN368 and a recording system with 24 channel $10 \mathrm{~Hz}$ geophones (sensor sm-4). A vibroseis was used as the seismic source. The 3-D seismic PSTM data set covered 215 square kilometres. In general, the quality of the data is good, with a good signalto-noise ratio that allows the deep horizons to be recognised. The interpretation of the top and bottom of the Mulussa $\mathrm{F}$ formation in the majority of the study area is clear. The average thickness of the latter formation is approximately $300 \mathrm{~m}$. The orientation of the inline is NE-SW. The lateral continuity of the internal seismic reflections of the Mulussa $\mathrm{F}$ formation is limited due to the depositional fluvial system.

Seismic facies analysis of the Mulussa F sequence

The concepts of seismic stratigraphy and facies analysis (Vail et al.1977) have been applied to the present study to characterise the internal geometry of the Mulussa $\mathrm{F}$ formation and interpret the various facies in terms of depositional environment and lithology. The main step is to define the seismic sequence separated by the major surfaces of discontinuity and the correlative continuity surface. These surfaces are interpreted as unconformities. In the stacked seismic sections, the distinct seismic sequence of the Mulussa $\mathrm{F}$ formation, and its constituent facies are recognised with the following characteristics:

\section{Mulussa F sequence}

The Mulussa $\mathrm{F}$ sequence was deposited before the main rifting phase that occurred during the late cretaceous (Coniacian). It is bounded by a truncation surface below, which is the top of Doubayat formation (Fig. 2), and it is bounded on top by a correlative continuity surface called the BKL. Reflections below the surface clearly dip toward the northeast and southwest. From point CDP 500-700, the sequence internal reflections paralleling the upper and lower correlative surfaces dip down steeply towards northeast at an apparent angle of almost $25^{\circ}$, then they rise up gradually to point $\mathrm{CDP} 700$, forming a concave-up geometry (Fig. 4). After that, the sequence reflections dip down gradually until point CDP 840 . From point CDP $500-255$, the sequence slants increasingly toward the southwest, at an apparent angle of $20^{\circ}$ (Fig. 4).

The Mulussa $\mathrm{F}$ sequence facies are characterised by a sub-parallel, parallel reflection pattern, poor to moderate continuity and medium amplitude. The amplitude is typically in the range of $70-80 \%$. This facies pattern is interpreted as a thick sand bed with interbedding shales deposited in a low-medium energy deltaic shelf margin. This pattern is typical of a fluvial environment (Sangree and Widmier 1978). Low-amplitude zones on a seismic section indicate that either the beds are too thin to be resolved by seismic methods or the deposits are uniform. 
Fig. 3 Time map of the Mulussa $\mathrm{F}$ formation including local structural units
Fig. 4 Seismic section (inline 2150) reveals the sequence of Mulussa $\mathrm{F}$ and other formations tops

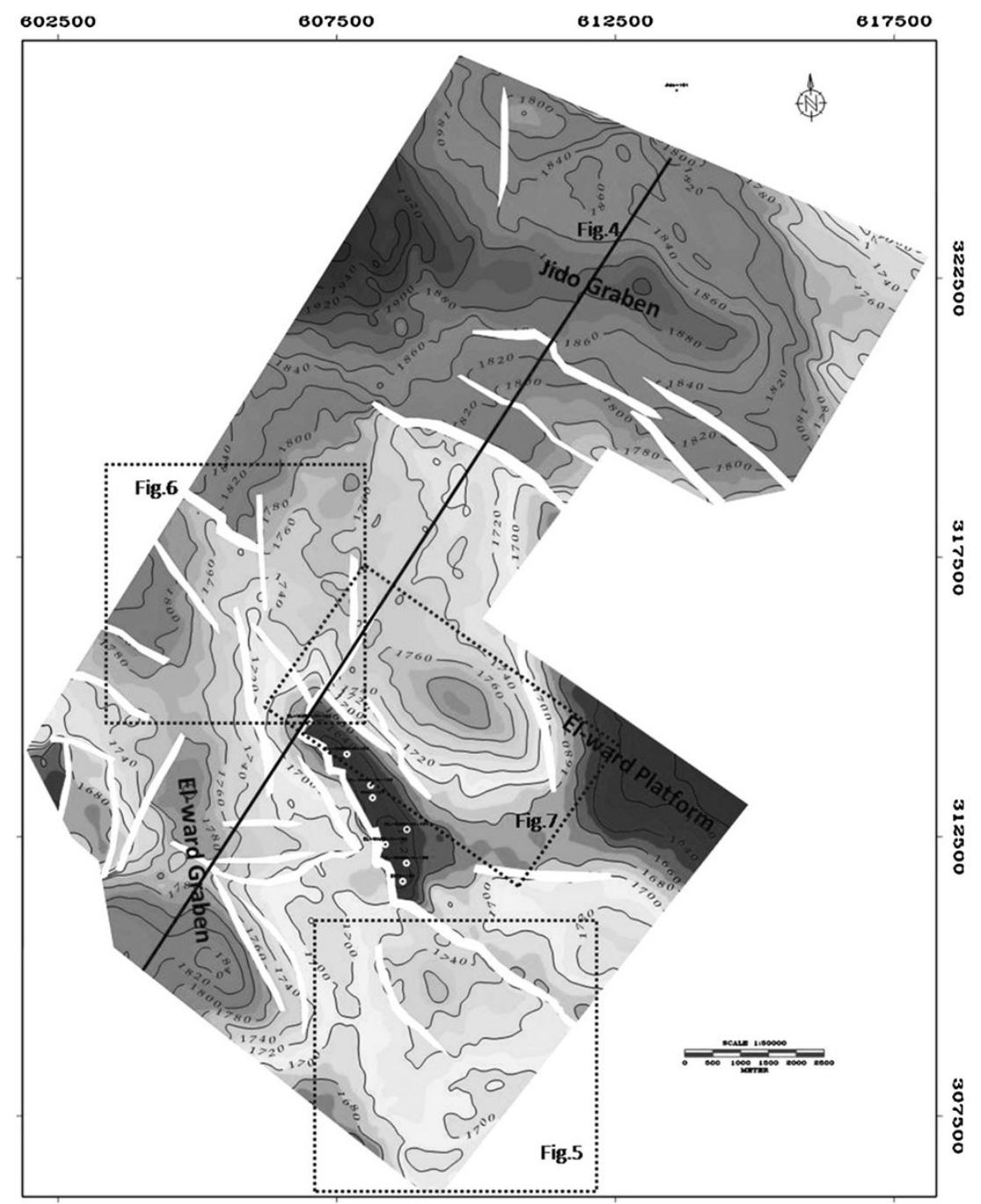

Good reflection amplitudes may represent interbedding of the relatively thick sandstones with the shales and siltstones. The thickness of the Mulussa F sequence decreases toward the southwest, i.e., in the direction of Rutba high, but it generally increases toward the northeast, i.e., in the direction of the Central Euphrates Graben (Figs. 1, 4). 
Delineating the fluvial channel system using 3-D seismic attributes

Seismic attributes extract information from seismic reflection data that can be used for quantitative and qualitative interpretation. Attributes are used by geophysicists and others to delineate depositional features. Some attributes, such as relative acoustic impedance and coherency volume, are directly sensitive to changes in seismic amplitude (Chopra and Marfurt 2005). Seismic attributes are commonly used for two purposes: detecting features and predicting physical properties of the formation of interest (Radovich and Oliveros 1998).

\section{Relative acoustic impedance (RAI)}

Delineating the fluvial channel system using the relative acoustic impedance attribute is a technique that relies on intrinsic physical property calculations for interface beds. As the calculations determine the density of the geological formation $(\rho)$ multiplied by the propagation velocity of P-waves (V) in the formation (Eq. 1) (Becquey et al. 1979).

$A I=\rho v$

The relative acoustic impedance has been shown by Taner (2000) to be expressed and computed by integrating the real part of the seismic trace. This method assumes that the input seismic data have been processed to reduce the noise and eliminate multiple contamination. Based on this assumption, the seismic trace represents the band-limited reflective series (Eq. 2) (Schlumberger. 2007a). The integration of the seismic trace provides a band-limited estimate of the natural logarithm of the acoustic impedance (Eq. 3) (Schlumberger 2007a).

$f(t)=\frac{1 \Delta \rho v}{2 \rho v}$

$\ln A I=2 \int_{t=0}^{t=T} f(T) \mathrm{dt}$

The relative acoustic impedance map is computed by integrating the attribute across the given time window. For example, the attribute can be integrated between two interpreted horizons. Physically, this is related to the logarithm of the acoustic impedance contrast. Variations in the integrated acoustic impedance attributes map are related by density variation, porosity, lithology and other features. Thus, the relative acoustic impedance map is used for reservoir characterisation (Taner et al. 1979).

Because the acoustic impedance attribute enhances impedance contrast boundaries, it may help to delimit different facies within a fluvial complex. In general, due to the lithological differences between channels and the

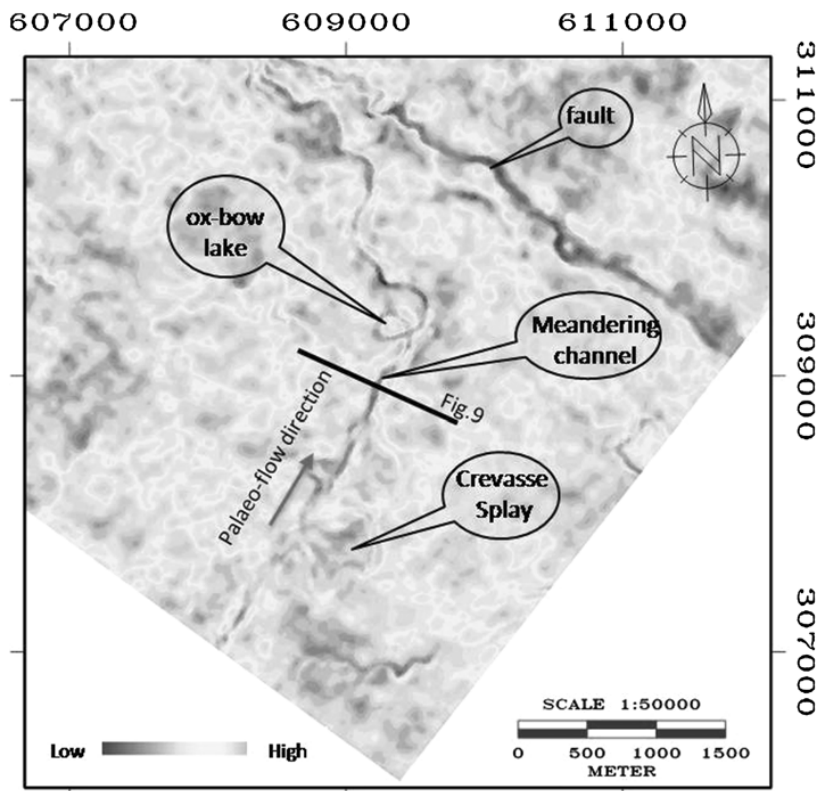

Fig. 5 Relative acoustic impedance attribute map within the Mulussa F sequence. The map shows an Ox-Bow lake, a crevasse splay and a meandering channel. It also highlights the impedance contrast boundaries and the changes in lithology

differences between channel fills and/or flood plains, the amplitudes of seismic reflections are obviously distinct, particularly if the difference in acoustic impedance is large.

Hence, we can delineate the fluvial channel system by calculating the acoustic impedance volume on the time interval of the Mulussa F Sequence, i.e., between two horizons: the top of Mulussa $\mathrm{F}$ and the top of Doubayat (Figs. 5, 6).

\section{Coherency}

The coherency attribute is calculated from 3-D seismic data. It is a quantitative measure of the similarity or dissimilarity of nearby seismic traces based on Eq. 4 (Bahorich and Farmer 1995).

$\Phi(t, d)=\frac{\sum_{k=t+N / 2}^{k=t+N / 2} G_{k} H_{k+d}}{\sqrt{\sum_{k=t+N / 2}^{k=t+N / 2} G_{k}^{2} \sum_{k=t+N / 2}^{k=t+N / 2} H_{k+d}^{2}}}$

In this equation, $\Phi$ is the correlation coefficient at time $(t)$ (milliseconds) for a specific geologic dip $(d) . G$ and $H$ are the correlated traces, and $N$ is the number of samples in the correlation time window.

Because the coherence measurements in three dimensions represent the trace-to-trace similarity, they produce interpretable changes (Chopra et al. 2011). Similar traces are mapped with high coherence coefficients and discontinuities, such as faults and fluvial channels, and subtle stratigraphic features have low coefficients. The regions of 
seismic traces cut by channels, for example, result in sharp discontinuities in the trace-to-trace coherence, producing delineation of low coherence along the channel profile. The significant details of stratigraphic features such as river channels, levees and submarine canyons are undetectable in seismic data even with close scrutiny. The attribute

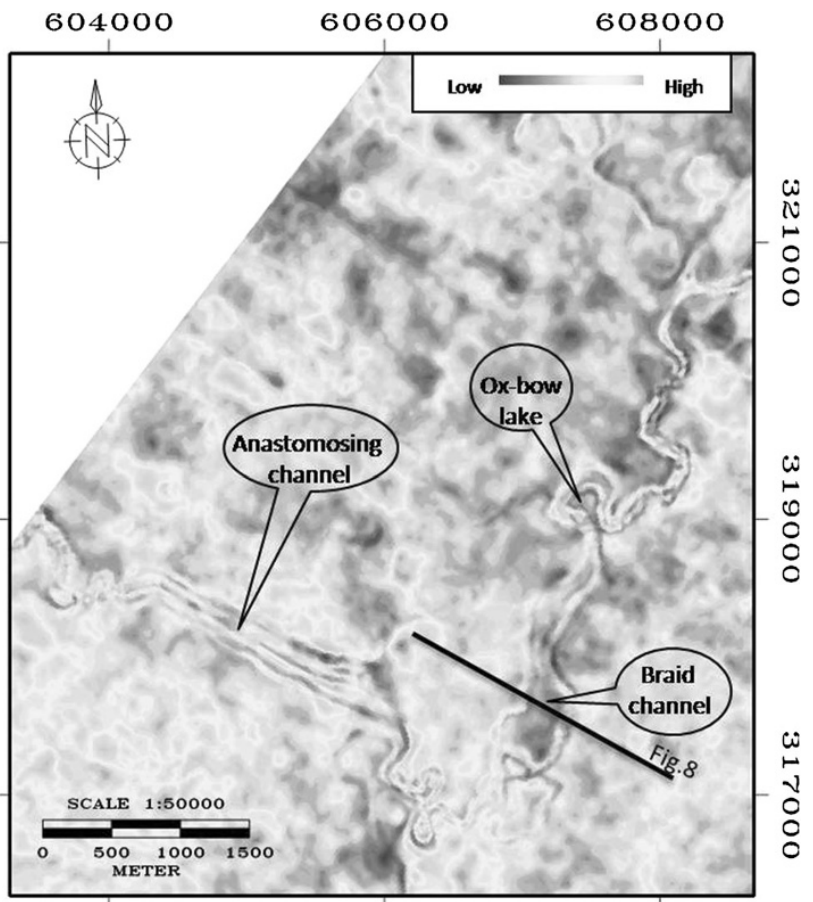

Fig. 6 Relative acoustic impedance attribute map within the Mulussa $\mathrm{F}$ sequence. The map shows the anastomosing channel and the braided channel involves a numeric process, which does not require any interpreted horizons, and so it is free from interpretational bias.

The coherence attribute map within Mulussa F contains different discontinuities, such as faults and channels. The black areas represent areas of high coherency, and the white areas represent features of low coherency, which likely include stratigraphic information (Fig. 7).

Fluvial channel types within the Mulussa F formation

In this study, the attribute maps illustrate a wide variety of fluvial channel types, dimensions, vertical successions, and lateral relationships. The mapped channels seem to have different sizes, as shown in Figs. 5, 6, 7. The differences are likely due to differences in the substratum erodibility, channel discharge (sediment supply and flow rate), and/or tectonic control. A braided channel is clearly observed in Fig. 6. Such a channel is created when a stream channel is divided into several smaller ones by the accumulation of channel deposits (Fig. 8a). By applying the reflection strength attribute on the previous seismic section in Fig. 8a, sandy beds with high reflection strength (light colour) can clearly be observed enclosed by shales with low reflection strength (grey colour) (Fig. 8b). The braided channel is approximately $2.3 \mathrm{~km}$ long in the study area, and the medium single channel is approximately $300-400 \mathrm{~m}$ wide.

A meandering fluvial channel is observed in the study area. It forms a sinuous curve, as shown in Figs. 5, 7. It moves in loops, and its velocity is greatest at the outer bank where erosion occurs and lowest at the inner bank where deposition of the point bar sands occurs. The length of the
Fig. 7 Meandering tributary channel mapped through the coherency attribute at time slice 1816 ms within the Mulussa $\mathrm{F}$ sequence (the dotted curve indicated with arrows)

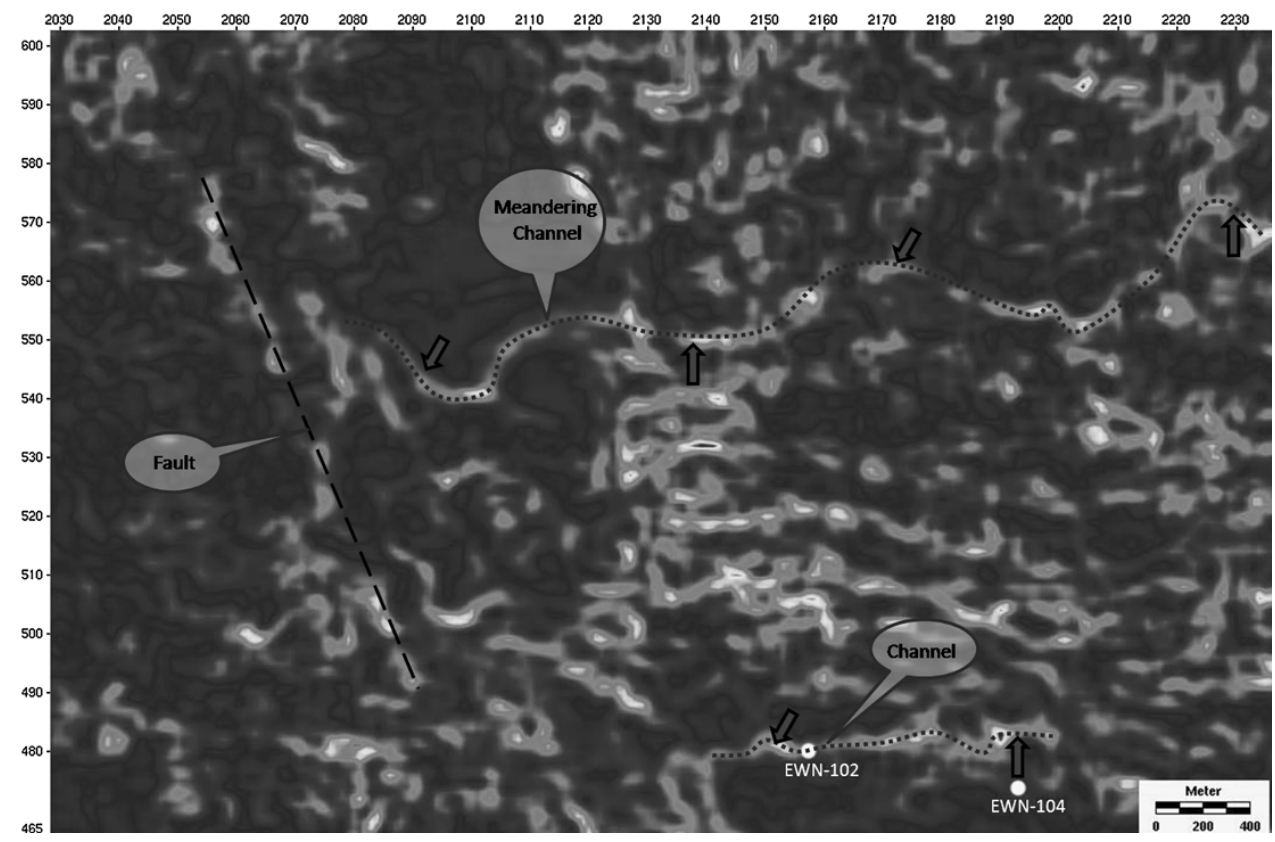




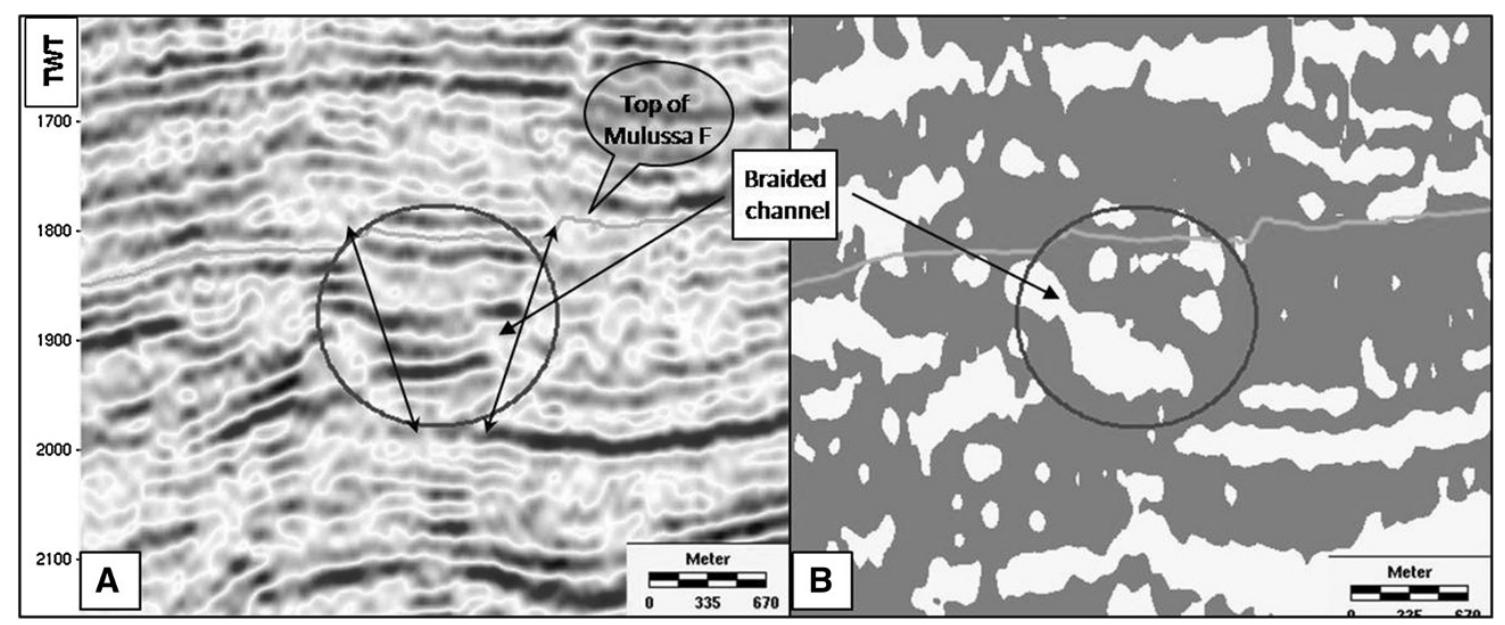

Fig. 8 a. Seismic section passing the braided channel. b Reflection strength attribute applied to the same section

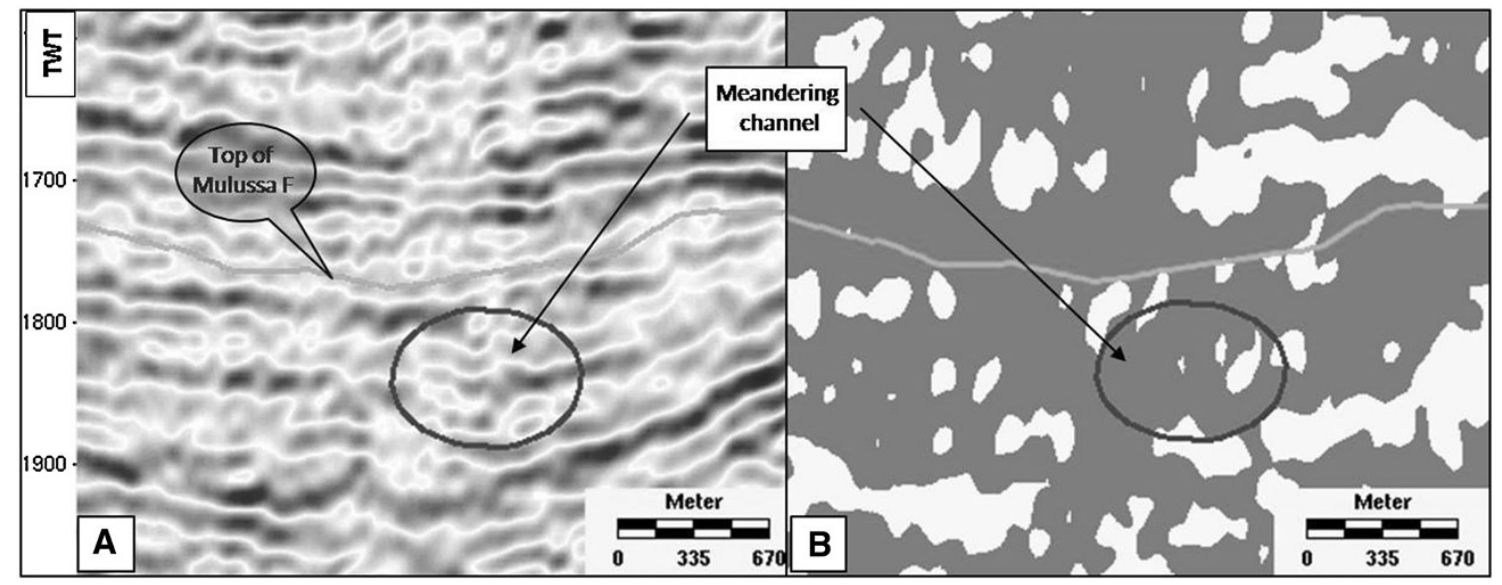

Fig. 9 a Seismic section passing the meandering channel. b Reflection strength attribute applied to the same section

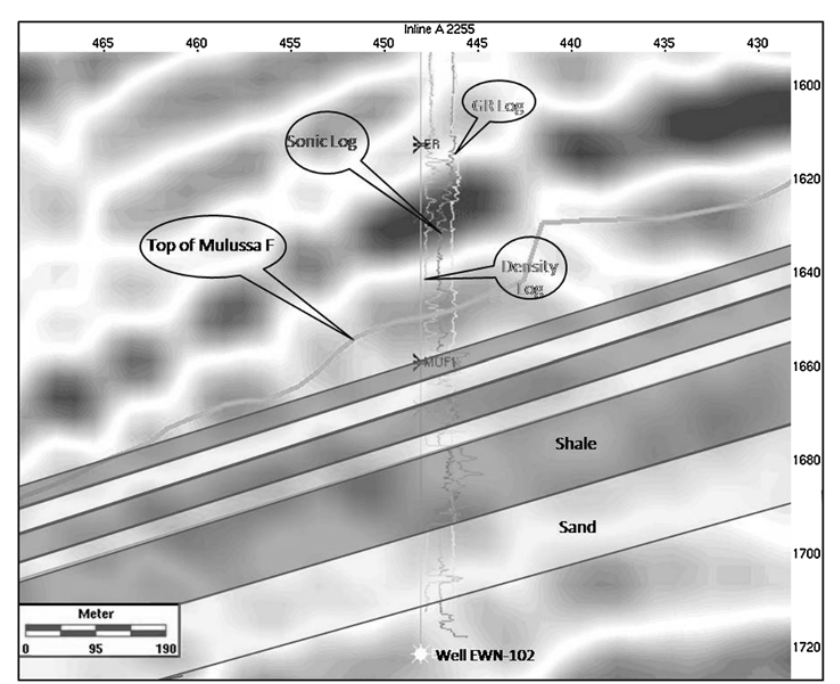

Fig. 10 Enlarged seismic section (cross-line 477) crossing the EWN102 well and showing alternating shale and sandstone beds measured by the well logs in the Mulussa $\mathrm{F}$ formation main meandering channel is estimated to be almost $24 \mathrm{~km}$, with an average width of $80 \mathrm{~m}$. The reflection strength attribute has been applied to a seismic reflection section (Fig. 9a) to infer the lithology of the channel fill. The figure shows that the channel fill mainly contains shales (grey colour) surrounding a little sandstone (light colour) (Fig. 9b).

The anastomosing channel is shown in Fig. 6. It forms three parallel straight channels. In general, it is defined as a branching, interlacing stream with a net-like appearance. It is traced on the attribute map, and it is approximately $2.5 \mathrm{~km}$ long.

The prediction of fluvial sandstone beds in the Mulussa $\mathrm{F}$ formation

Along the mapped meandering channel profile, there are plenty of point bar sandstone beds, some of which may contain stratigraphical hydrocarbon traps. Shale bed filled

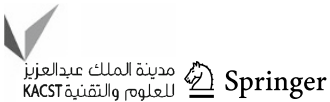


Fig. 11 A seismic section (part of inline 2150) flattened on the Mulussa $\mathrm{F}$ formation top (the black horizon) showing increasing formation thickness as the terrain dip gradient increases

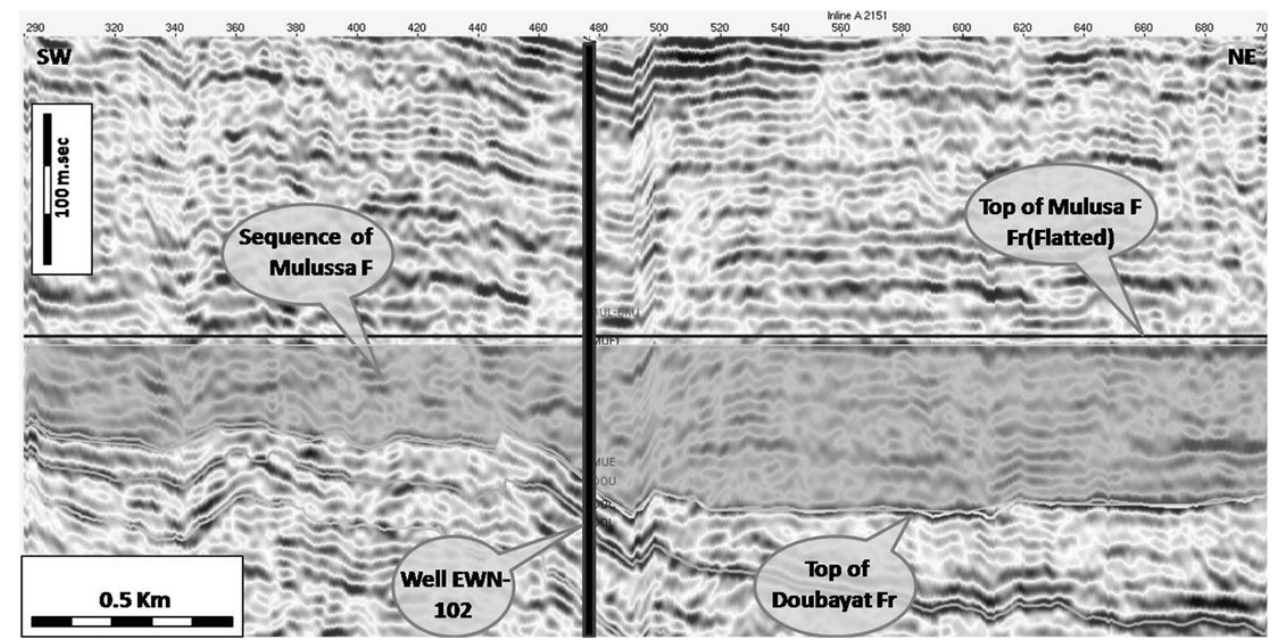

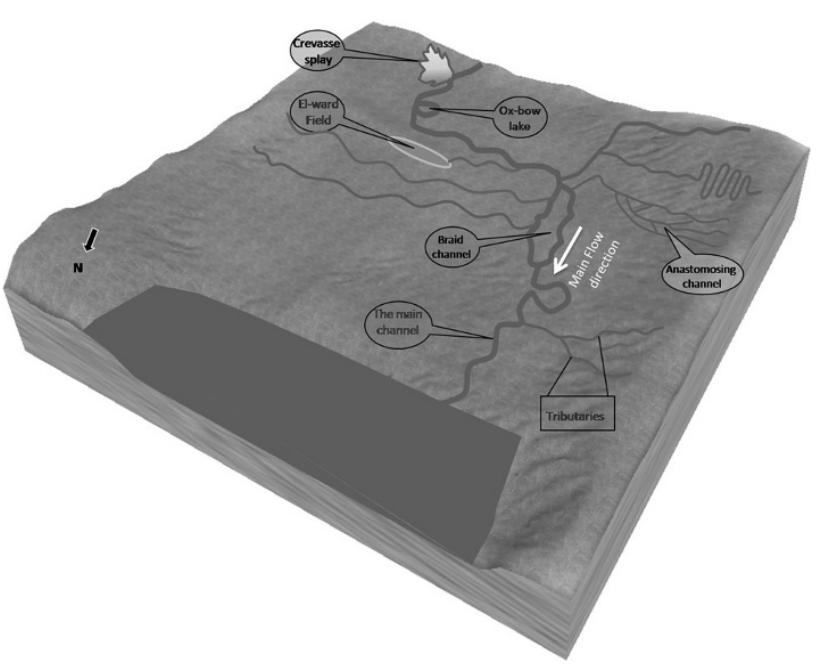

Fig. 12 Schematic depositional model of the Mulussa $\mathrm{F}$ formation in the Upper Triassic. The distribution of different channels system based on attribute maps is shown

channels spread widely across the floodplain within the Mulussa $\mathrm{F}$ and form seal rocks that fully surround the point bar, crevasse splay and ox-bow sandstone beds. Some shale-filled channels intersect in the Elward field wells. For example, the EWN-102 well is shown in Fig. 7. The central portions of the compacted shale-filled channels within the Mulussa $\mathrm{F}$ formation range from 20 to 25 metres, as measured on the well logs (Fig. 10).

\section{Depositional model of the Mulussa F sequence}

Integrating seismic data, log data, paleo-structural analysis and channels style information enables reconstruction of the depositional model of the Mulussa F formation Channels. The seismic section flattened on the Mulussa $\mathrm{F}$ formation top (inline 2150 in Fig. 4) shows an almost slight dip and uniform thickness until it reaches the EWN-102 well. Then, its thickness becomes suddenly larger due to an increasing terrain dip gradient at the braided channel (Fig. 11). The parallel reflection configurations indicate deposition over semi-flat surfaces during a tectonic serenity period. Palinspastic analysis shows paleo-highs along the eastern and western wings of the study area, from which a set of tributaries declines toward the main channels. A reconstructed depositional model of various channel styles is shown in Fig. 12.

\section{Results and discussion}

The coherence and relative acoustic impedance maps (Figs. 5, 6, 7) display better delineation of the channels at locations that correspond to crevasse splay, ox-bow lake facies and different fluvial systems such as the braided, anastomosing and meandering channels.

The coherence image clearly reveals several discrete meandering channels, as indicated by the dotted curve in Fig. 7 (low coherency white area). It also shows numerous subtle faults and other discontinuities inside the Mulussa F sequence.

The presence of various channels, as indicated in the attribute map (Fig. 6), provides significant information about the paleo-relief, the river discharge and the direction in the Upper Triassic period. The anastomosing channel occurs in the regions of low stream gradient. The relative acoustic impedance map indicates that the paleo-flow channel is directed to the southeast, near Rutba high, whereas the braided channel indicates that the river channel was not very stable during the deposition of the Mulussa $\mathrm{F}$ formation. This style is usually created in the areas of steep dips and large supply sediments and in areas where the discharge of the river fluctuates daily or annually (Walker 1984). However, based on the aforementioned attribute maps and palinspastic restoration analysis, the main paleo- 
Fig. 13 A schematic diagram showing the water level during deposition of the Mulussa $\mathrm{F}$ formation

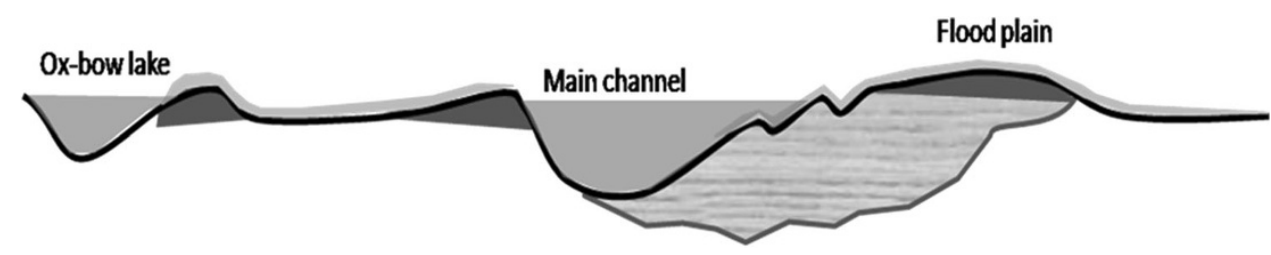

flow direction was toward the northeast, from Rutba high to the Central Euphrates, whereas the paleo-flow directions of all tributaries were toward the larger main channel.

Coarse sandy channel deposition reflects a high-energy environment, and a muddy flood plain reflects a low-energy environment. These features are obvious in the seismic sections. The first one is a strong reflection, and the other has good reflection continuity (Yuhua et al. 2005).

The lithology within the channels can be inferred from the reflection strength attribute (Figs. 8, 9), which is used as an effective indicator to show the acoustic impedance contrast. Consequently, the reflection strength attribute is useful for recognising the stratigraphic variations within the fluvial channels (Walls et al. 2002). As a result of integrating the reflection configurations, the relative acoustic impedance attribute and the nearby well data, it can be concluded that the mapped channels are mainly filled with shaly beds of relatively low impedance (dark colour), whereas the sandy beds have high impedance (light colour) and are surrounded by shale beds that were deposited on the channel banks, point bars and crevasse splays, as shown in Figs. 5, 6. All of these features may be formed by high-quality potential stratigraphic hydrocarbon reservoirs that are rich in sandstones. Hence, researchers try to concentrate on the exploration of undiscovered potential traps due to uncertainties in the prediction of their distributions. A lack of understanding about the reservoir spatial distribution limits the drilling of wells in the locations of stratigraphic traps within the Mulussa $\mathrm{F}$ formation.

Fluvial systems react to changes in the base level (Martin et al. 2011), which can be defined as the level at which a stream can no longer erode its bed. This level corresponds to sea level for rivers that flow into the sea. Changes in the base level cause changes in the shape, width, and depth of fluvial channels (Blum and Tornqvist 2000). In addition, other factors such as sea-level variations, tectonic events, and changes in fluvial discharge play a significant role in determining the stream shape via controlled erosion and deposition processing.

The Euphrates Graben area experienced a wet climate in the Upper Triassic period, which led to an abundant discharge of water loaded with sediments into the basin across many fluvial channels. At the same time, the tectonic serenity period prevailed in the study area, as indicated in the seismic data. These factors, along with sea-level rises, can be used to interpret the reason for the creation of unincised channels within the Mulussa $\mathrm{F}$ formation. It is generally known that incised channels are formed by at least three main mechanisms (Posamentier 2001): (1) as a result of sea-level fall, (2) by tectonic tilting of alluvial settings, or (3) during significant decreases in fluvial discharge. Based on the aforementioned information, it can be concluded that the Mulussa F formation was deposited on the continental fluvial deltaic depositional basin by unincised fluvial channels. The river water level was likely close to the flood plain level during deposition (Fig. 13).

\section{Conclusion}

3-D seismic data have been interpreted using powerful seismic volume attribute techniques. The braided, meandering and anastomosing channels, in addition to the associated fluvial facies, have been mapped. The attribute shows that the sandstones surrounded by shaly beds have higher impedance and were deposited on the channel bank, point bar and crevasse splay. These fluvial facies are considered to be high-quality potential hydrocarbon reservoirs that could be future exploratory targets. Many of the channels indicate that a wet climate prevailed in the Euphrates Basin region in the Upper Triassic period. Water discharge and sea-level rises may have contributed to creating the unincised channels. The presence of various types of fluvial channels provides important information about the paleorelief during the deposition of the Mulussa F Formation.

Acknowledgments This article was prepared under the supervision and permission of the Syrian Petroleum Company (SPC). The authors would like to thank the staff of the Syrian Petroleum Company, especially $\mathrm{Mr}$ Wasef Al-Himed, Exploration Manager, for close cooperation and for the permission to publish this paper including the seismic profiles.

Open Access This article is distributed under the terms of the Creative Commons Attribution License which permits any use, distribution, and reproduction in any medium, provided the original author(s) and the source are credited.

\section{References}

Bahorich M, Farmer S (1995) 3-D seismic discontinuity for faults and stratigraphic features, The coherence cube. Lead Edge $17: 1053-1058$

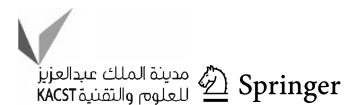


Becquey M, Lavergne M, Willm C (1979) Acoustic impedance logs computed from seismic traces. Geophysics 44(9):1485-1501

Best JA, Barazangi M, Al-Saad D, Sawaf T, Gebran A (1993) Continental margin evolution of the northern Arabian Platform in Syria. Am Assoc Pet Geol Bull 77(2):173-193

Blum MD, Tornqvist TE (2000) Fluvial responses to climate and sea level change, a review and look forward. Sedimentology 47:2-48

Brew G, Lupa J, Barazangi M, Sawaf T, Al-Imam A, Zaza T (2001a) Structure and tectonic development of the Dead Sea Fault System and Ghab Graben in Syria. J Geol Soc 158(4):665-674

Brew G, Barazangi M, Al-Maleh AK, Sawaf T (2001b) Tectonic and geologic evolution of Syria. GeoArabia 6(4):573-616

Chopra S, Marfurt K (2005) SEG75th Anniversary, Seismic attributes-a historical perspective. Geophysics 70:3-28

Chopra S, Misra S, Marfurt K (2011) Coherence and curvature attributes on preconditioned seismic data. Lead Edge 30(4):386-393

Litak RK, Barazangi M, Beauchamp W, Seber D, Brew G, Sawaf T, Al-Youssef W (1997) Mesozoic-Cenozoic evolution of the intraplate Euphrates fault system, Syria: implications for regional tectonics. J Geol Soc 154(4):653-666

Litak RK, Barazangi M, Brew G, Sawaf T, AL-Imam A, ALYoussef W (1998) Structure and evolution of the petroliferous Euphrates Graben System, Southeast Syria. Am Assoc Pet Geol Bull 82(6): 1173-1190

Martin J, Cantelli A, Paola C, Blum M, Wolinsky M (2011) Quantitative modeling of the evolution and geometry of incised valleys. J Sediment Res 81:64-79

McClusky S, Balassanian S, Barka A, Demir C, Ergintav S, Georgiev I, Gurkan O, Hamburger M, Hurst K, Kahle H, Kastens K, Kekelidze G, King R, Kotzev V, Lenk O, Mahmoud S, Mishin A, Nadariya M, Ouzounis A, Paradissis D, Peter Y, Prilepin M, Reilinger R, Sanli I, Seeger H, Tealeb A, Toksöz MN, Veis G
(2000) Global Positioning System constraints on plate kinematics and dynamics in the eastern Mediterranean and Caucasus. J Geohys Res 105(B3):5695-5719

Posamentier HW (2001) Low stand alluvial bypass systems, incised vs unincised. Am Assoc Pet Geol Bull 85:1771-1793

Radovich BJ, Oliveros RB (1998) 3D sequence interpretation of seismic instantaneous attributes from the Gorgon field. Lead Edge 17(9):1286-1293

Sangree JB, Widmier M (1978) Seismic stratigraphy and global changes of sea level, Part 9: seismic interpretation of clastic depositional facies. Am Assoc Pet Geol Bull 62:752-771

Schlumberger (2007a) Interpreter's guide to seismic attributes. http:// www.rocksolidimages.com/pdf/attrib_revisited.htm. Accessed 22 Jun 2006

Taner MT (2000) Attributes revisited, rock solid images. http://www. rocksolidimages.com/pdf/attrib_revisited.htm. Accessed 10 Apr 2009

Taner MT, Koehler F, Sheriff RE (1979) Complex seismic trace analysis. Geophysics 44:1041-1063

Vail PR, Mitchum RM, Thompson S (1977) Seismic stratigraphy and global changes of sea level, part 4, global cycles of relative changes of sea level. Am Assoc Pet Geol Bull 26:83-97

Walker R (1984) Facies model, Geoscience Canada, Geological Association of Canada, Reprint series 1, Toronto, pp 71-89

Walls JD, Taner MT, Taylor G, Smith M, Carr M, Derzhi N, Drummond J, McGuire D, Bregar S, Lakings J (2002) Seismic reservoir characterization of a US Midcontinent fluvial system using rock physics, poststack seismic attributes, and neural networks. Lead Edge 21:428-436

Yuhua B, LiYuhai FZ, Bao L (2005) The study and practice of fluvial sandstone reservoir prediction in Gangdong Oilfield. SEG Annual Meeting, Houston, Texas 